\title{
Economics Department
}

Informed Trading, Investment, and Welfare

JAMES DOW

and

ROHIT RaHI

ECO No. $97 / 3$

\section{EUI WORKING PAPERS}

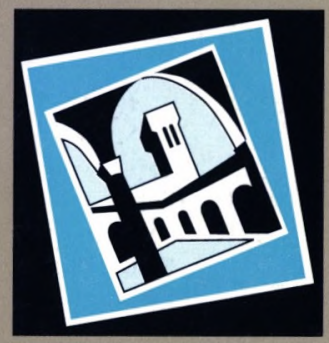

EUROPEAN UNIVERSITY INSTITUTE 
EUROPEAN UNIVERSITY INSTITUTE

||||||||||||||||||||||||||||||||||||||||||||||||||||||||||||

300010025 75092 


\section{EUROPEAN UNIVERSITY INSTITUTE, FLORENCE}

ECONOMICS DEPARTMENT

EUI Working Paper ECO No. 97/3

Informed Trading, Investment, and Welfare

JAMES DOW

and

ROHIT RAHI 
All rights reserved.

No part of this paper may be reproduced in any form without permission of the authors.

C)James Dow and Rohit Rahi

Printed in Italy in March 1997

European University Institute

Badia Fiesolana

I - 50016 San Domenico (FI)

Italy 


\author{
James Dow \\ Department of Economics \\ European University Institute \\ Badia Fiesolana \\ I-50016 San Domenico di Fiesole (FI), Italy \\ Email: dow@datacomm.iue.it \\ and

\section{Rohit Rahi} \\ Department of Economics \\ Birkbeck College, University of London \\ 7-15 Gresse Street, London W1P 2LL, U. K. \\ Email: rahi@ricardo.econ.bbk.ac.uk
}

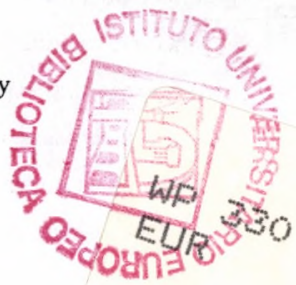

First draft: October 1996

This version: November 17, 1996

* Dow is on leave from London Business School. We have benefitted from the feedback of seminar audiences at Cambridge, Southampton, and University College London. This research is partiy funded by the European Commission TMR Network on Financial Market Efficiency and Economic Efficiency, grant no. FMRX-CT96-0054. 


\begin{abstract}
This paper studies the welfare economics of informed trading in a stock market. We model the effect of more informative prices on investment, given that this dependence will itself be reflected in equilibrium prices. We show that in rational expectations equilibrium with price-taking competitive behaviour, and in the presence of risk-neutral uninformed agents, uninformed traders cannot lose money on average to informed traders. However, some agents with superior information may be willing to lose money on average in order to improve their hedging possibilities. We provide a parametric model that allows a closed-form solution and a complete welfare snalysis. While a higher incidence of informed speculation always increases firm value through a more informative trading process, the effect on agents welfare depends on how revelation of information changes risk-sharing opportunities in the market.

Journal of Economic Literature Classification Numbers: G14, G18, D82, D60 Keywords: Speculation, Information Revelation, Feedback Effect, Market-Maker.




\section{Introduction}

This paper is about the analysis of security markets in terms of their effect on overall economic welfare, in a setting where agents in the economy have asymmetric information. We address the following important question: is a stock market trader, who trades with the motive of making profits on the basis of superior private information, socially beneficial? Does he confer a benefit on the economy, or are his profits made merely by draining resources from others? In this paper we do not attempt an unequivocal answer to this question, since the answer in any given instance must depend on the relative importance of a number of different pros and cons, but we do attempt to provide an improved framework for analyzing the issue.

A widely accepted view among economists is that the profits made by informed traders are like a tax on other investors (although they differ as to the nature of any offsetting benefits). To cite two examples that are explicitly concerned with public policy: Tobin (1978) has been influential in promoting the view that speculative profits do not have any offsetting benefit (he focuses specifically on short-term profits, however); King and Roëll (1988) suggest that profits to better-informed traders cause a corresponding reduction in the returns of other investors and hence depress investment by reducing market participation. Manove (1989) expresses this "adverse selection" view clearly:

Insider traders and informed speculators appropriate some part of the returns to corporate investments at the expense of other shareholders. This misappropriation ... tends to discourage corporate investment and reduce the efficiency of corporate behaviour.

In contrast, Manne (1966, p. 61) explicitly rejects this argument:

The insider's gain is not made at the expense of anyone. The occasionally-voiced objection to insider trading - that someone must be losing the specific money the insiders make-is not true in any relevant sense.

In this paper, we show that Manne's argument, quixotic as it may seem, can indeed be reconciled with a rational expectations model of the stock market. In our model, uninformed investors do not lose, on average, to the informed. We would argue that this is important not only as a theoretical result, but also because the amount of any "tax" or "lemons premium" 
that uninformed investors might (in an alternative model, or in reality) lose to the informed is unlikely to be a quantitatively significant part of the total return, in contrast to the used car market (Akerlof (1970)). Hence, it seems desirable to explore models where losses by the uninformed are not important.

Before proceeding further, we stress that this paper is about traders with superior private information, and not about insider traders. Superior information, in this paper, should be interpreted to mean a better insight into economic conditions, or into the financial analysis of an individual company. Active fund managers, stock market analysts, and others attempt to produce this kind of information to obtain higher returns. Insider trading, on the other hand, is a situation where an individual profits from information even though he does not have property rights over the information that allow him to do so. The problem of insider trading is a problem of misappropriating property rights. Unfortunately, much of the academic literature has failed to appreciate the distinction between insider trading and other kinds of informed trading and simply uses "insider trading" as a generic term to describe all informed trading.

The presence of informed traders in a market tends to make the price more efficient, i.e. to reflect their information (Roberts (1967)). A very large body of empirical research has investigated the efficiency of prices, and the view that more informative prices are also economically more efficient has often been held as axiomatic (Fama (1976, p. 133)):

An efficient capital market is an important component of a capitalist system ... if the capital market is to function smoothly in allocating resources, prices of securities must be good indicators of value.

However, it has proved harder to provide standard models where efficient prices lead to better investment and allocative decisions. This point is made by Holmström and Tirole (1993):

There is a vast literature in finance devoted to the analysis of information flows in stock markets, including how completely and how fast information is incorporated into prices. But in almost no model is information collection socially useful.

In this paper, we model how stock prices guide investment decisions (in contrast to Holmström and Tirole, who model the role of stock prices in improving managerial incentives). 
The effect may initially appear straightforward: if the stock price rises, this signals good information to the firm and investment will rise. However, if traders know that investment will respond in this way to prices, then prices themselves must adjust to reflect this dependence. This is the "feedback effect" described by Bresnahan, Milgrom and Paul (1992, p. 213, fn 16):

we assume ... there are no tricky gaming issues between management and the outsider traders. Suppose, for example, that the manager will withdraw the project if the stock market reaction is adequately adverse. Then the value of the security reflects this prospect ...

In this paper, we do model the feedback effect in equilibrium. Stock prices influence investment, and this dependence is incorporated into the equilibrium price formation process. Furthermore, we allow uninformed traders to make inferences from the volume of trade as well. A reasonable notion of equilibrium should permit agents to condition on any publicly available information, and trading volume is an obvious candidate. As with prices, volume influences investment and is in turn affected by it.

Another role of the stock market is to allocate risk, and the theory of financial markets has emphasized this aspect (Arrow (1953), Diamond (1967), Allen and Gale (1994)). However, models of informed trading have generally not captured this role. Some models have relied on exogenous "liquidity traders" or "noise traders" who trade random amounts to prevent the price from being fully revealing. These exogenous shocks can be endogenized by, instead, introducing risk-averse agents with endowment shocks. This was done by Diamond and Verrecchia (1981) in the framework of the rational expectations equilibrium models since Grossman (1977) and Grossman and Stiglitz (1980). Similarly, Spiegel and Subrahmanyam (1992) and Glosten (1989) introduced endowment shocks to endogenize the noise trade of the market-maker models of Kyle (1985) and Glosten and Milgrom (1995), respectively. In these papers the hedgers face a trade-off: they lose money on average by participating in the market, but they are able to insure their risky endowments.

In this paper, the role of informational efficiency in altering risk-sharing opportunities for hedgers is different. Hedgers do not necessarily lose money by participating in the market. The appropriate criterion to consider, however, is not whether uninformed traders lose money but whether informed trading increases their expected utility. We are able to do this because we explicitly model the objectives of these traders (models with liquidity 
traders cannot be used to analyze their welfare, although many authors have been tempted to do so). The effect of informed trading on the welfare of the uninformed is ambiguous. An agent with a hedging need may be made worse off in a more informative market because the risk factor he needs to hedge is revealed by the security price before he has a chance to put his hedging position in place: this is the "Hirshleifer effect" (Hirshleifer (1971)). On the other hand, if other risk factors that are not correlated with his endowment are revealed early, his hedging opportunities are improved as the security is now more closely correlated with his risk exposure. Marín and Rahi $(1995,1996)$ have previously studied these effects in analyzing financial innovation and intraday trading patterns.

To summarize the discussion so far, this paper presents a model where informed traders make superior profits, but these profits are not at the expense of the uninformed. The presence of the informed traders makes prices and volume more informative and this improves investment efficiency, while altering risk-sharing opportunities.

To analyze the welfare effects of informed trading, we use a model where all agents are rational utility-maximizers. We first set out the model in a general form: it features a firm owned by risk-neutral shareholders, and traders who may have private information as well as hedging needs. We analyze rational expectations equilibria of the model, in which all agents are competitive price-takers. We show that in our setting, uninformed agents who trade for hedging reasons cannot lose money on average to informed agents. We then consider a parametric specification of the model with one type of informed agent and two types of 0 hedgers. We compute the equilibrium of the model and the ex ante expected utilities of all agents.

Many papers have addressed questions similar to ours. Manove (1989), Dennert (1990), Ausubel (1990) and Bhattacharya and Nicodano (1995) study the "adverse selection effect" where uninformed traders lose to informed, and this depresses ex ante investment levels that are chosen before trading in shares takes place. In contrast, in our model there is no adverse selection effect, and investment responds to contemporaneously determined share prices.

Leland (1992) attempts to address these issues by modelling the effect of the stock price on investment, but does so in a setting where the firm does not learn anything from the stock price, and where investment is not chosen to maximize shareholder value. Hence, there is no feedback effect. Henrotte (1992) models the effect of security prices on a firm's output decisions, in the spirit of our feedback effect. However, his security is a futures 
contract on the firm's output and hence a change in firm value does not directly affect the security value. Fishman and Hagerty (1992) model an industry where potential entrants are guided by incumbents' stock prices, and this may have a feedback effect on the incumbents' profitability and hence their share price. Boot and Thakor (1996) and Dow and Gorton (1995) do model the feedback effect fully (Dow and Gorton (1995) also incorporate a managerial incentive problem that can be remedied with stock-price based compensation). However, they use exogenous liquidity traders rather than rational hedgers. Habib et al. (1996) model a feedback effect without noise traders, and with full revelation with respect to the asset payoff. Their model (an analysis of spin-offs) is not adapted to address the welfare questions that are the focus of this paper.

This paper is also related to the many papers on noisy rational expectations equilibria (e.g. Grossman (1977), Grossman and Stiglitz (1980)) and the market-maker variants (Kyle (1985)), which incorporate monopolistic behaviour and market orders. In terms of models in the existing literature, the parametric version of our model may be described as a variant of Diamond and Verrecchia (1981) where we have allowed for the feedback effect of prices and volume into investment policy, and where we have assumed the presence of risk-neutral uninformed traders. We have also made some specific assumptions on the types of traders in the model, notably that no agent has both a hedging need and private information about the asset payoff (hence our agents are either speculators or hedgers).

We proceed as follows. In Section 2 we set out a general model of a security market with agents who trade for informational and hedging motives, that includes the feedback effect. We prove the "no-loss" result: hedgers who have no information other than publicly available market information cannot lose money to informed traders (Proposition 2.1). Section 3 presents the parametric model with the equilibrium computed as Proposition 3.1. In Section 4, we compute the equilibrium ex ante expected utilities (Proposition 4.1) and present comparative statics results (Proposition 4.2). Section 5 concludes. All proofs, except for that of Proposition 2.1, are in the Appendix.

\section{A General Model}

We consider a firm, the value of whose productive assets is given by

$$
v=f(k, y),
$$

where $k$ represents the level of investment, and $y$ is a random variable affecting profitability. 
We normalize the number of outstanding shares to one. In addition to these shares a riskless bond is available for trade, which we take to be the numeraire, normalizing the interest rate to zero. The original owner of the firm (agent 0 ) is risk-neutral. There are $n$ other agents who trade to exploit superior information or to hedge their risk exposures. All agents are competitive price-takers (i.e. each should be interpreted as a continuum of infinitesimal traders). Agent $i(i=1, \ldots, n)$ has a von Neumann-Morgenstern utility function $U_{i}$, and a stochastic endowment $e_{i}$. He privately observes $\left(s_{i}, x_{i}\right)$, where the signal $s_{i}$ is correlated with the firm's profitability parameter $y$ and $x_{i}$ parameterizes the agent's risk exposure to a random variable $z$. Taking an asset position $t_{i}$ at the market price $p$ leaves him with terminal wealth

$$
w_{i}=e_{i}\left(x_{i}, z\right)+t_{i}(v-p) .
$$

DEFINITION 1. A rational expectations equilibrium is a price function $p\left(s_{1}, \ldots, s_{n}, x_{1}, \ldots, x_{n}\right)$, order flow $t\left(s_{1}, \ldots, s_{n}, x_{1}, \ldots, x_{n}\right)$, a trade $t_{i}$ for each agent $i=1, \ldots, n$, and an investment level $k$, such that:

(a) $t_{i} \in \arg \max E\left[U_{i}\left(w_{i}\right) \mid s_{i}, x_{i}, p, t\right], \quad(i=1, \ldots, n)$,

(b) $t=\sum_{i=1}^{n} t_{i}$,

(c) $p=E(v \mid p, t)$, and

(d) $k \in \arg \max E(v \mid p, t)$.

Note that agents know the price and order flow functions and learn from their observation of prices and order flows. In particular the firm is guided in its investment decisions by the information aggregated and conveyed by prices and order flows. Simultaneously the price and order flow themselves reflect this dependence. Since agent 0 is risk-neutral and competitive, he determines the price through condition (c), and absorbs the aggregate trade of the other agents. This ensures market-clearing.

We use the terms "order flow" and "trading volume" interchangeably. This definition of trading volume as the aggregate trade of agents 1 through $n$ excludes agent 0 who can be viewed as a market-maker à la Kyle (1985). We will find it convenient to adopt this market-maker interpretation in what follows.

Proposition 2.1. Suppose an agent $i$ 's private information signals $\left(s_{i}, x_{i}\right)$ are degenerate random variables. Then in equilibrium his expected trading profits are zero on each trade. Any agent whose ex ante expected trading profits are negative must have better information in equilibrium than the market-maker. 
Proof. An agent with null private information nevertheless learns from prices and the order flow. His expected trading profit on a position $t_{i}$ is $t_{i}[E(v \mid p, t)-p]$ which is zero by condition (c) in Definition 1. It immediately follows that any agent with nonzero expected trading profits has more information than is revealed by $(p, t)$, which is the market-maker's information.

Note that an agent with null private information has exactly the same information as the market-maker. Paradoxically, a trader does not lose money unless he has better information than the market-maker. Indeed, traders who lose money do so deliberately because this allows them to construct a better hedging strategy than by simply breaking even on each trade. In contrast traders with no private information cannot make (expected) losses no matter how hard they try. This "no-loss" result clearly holds whether or not informed traders behave strategically.

In order to develop the intuition of these results in greater detail, and to carry out a complete welfare analysis that includes both the feedback effect of stock prices on investment and the effect of asymmetric information on hedgers' utilities, we now study a parametric version of the model.

\section{A Parametric Model}

In this section we consider specific forms for the functions and random variables of the model just described. The value of the firm is given by

$$
v=k y-\frac{c}{2} k^{2},
$$

where $y$ denotes the profitability per unit of investment, and $c$ is a (positive) investment cost parameter. All traders are infinitesimal price-taking agents. There is a measure $q_{S} \in(0, \infty)$ of identical privately informed speculators who observe a signal $s$ that is correlated with $y$. A speculator has no endowment. Taking an asset position $t_{S}$ at the market price $p$ leaves him with terminal wealth

$$
w_{S}=t_{S}(v-p)
$$

In addition there are two types of hedgers who are exposed to the random variable $z$. The risk exposure of a hedger of type 1 is itself random: his initial endowment is $e_{1}=x z$ (where $x$ is random). After privately observing $x$, he trades an amount $t_{1}$ which results in net wealth

$$
w_{1}=x z+t_{1}(v-p) .
$$


A hedger of type 2 has a constant risk exposure with endowment $e_{2}=z$, and trades $t_{2}$ to realize terminal wealth

$$
w_{2}=z+t_{2}(v-p)
$$

There is a measure $q_{1} \in(0, \infty)$ of type 1 hedgers and we normalize the mass of type 2 hedgers to be one. For convenience we will henceforth refer to an individual speculator as "the speculator" and likewise to a hedger of type $i$ as "hedger $i . "$

Agent $i(i=S, 1,2)$ has constant absolute risk aversion $r_{i}$ and has information $\mathcal{I}_{i}$, i.e. $\mathcal{I}_{S}$ is the partition generated by observing $(s, p, t)$, and similarly $\mathcal{I}_{1}$ is induced by $(x, p, t)$ and $\mathcal{I}_{2}$ by $(p, t)$. All random variables are joint normally distributed. Without loss of generality we can take $y=s+\epsilon$ where $s$ is independent of $\epsilon$. We assume that

$$
\left(\begin{array}{l}
s \\
\epsilon \\
z \\
x
\end{array}\right) \sim N\left[0,\left(\begin{array}{cccc}
V_{s} & 0 & V_{z s} & 0 \\
0 & V_{\epsilon} & V_{z \epsilon} & 0 \\
V_{z s} & V_{z \epsilon} & V_{z} & 0 \\
0 & 0 & 0 & V_{x}
\end{array}\right)\right]
$$

We use the following notational convention: for random variables $g$ and $h, V_{g h}:=\operatorname{cov}(g, h)$. Also $\rho_{g h}$ denotes the correlation coefficient between $g$ and $h$, and $\beta_{g h}:=V_{g h} V_{h}^{-1}$ is the coefficient from the regression of $g$ on $h$ (the "beta" of $g$ with respect to $h$ ).

In general, the risk $z$ may be correlated with both $s$ (the predictable component of $y$ ) and $\epsilon$ (the residual), and these correlations may be different. The magnitude of hedger 1's risk exposure, $x$, is independent of all other random variables. We assume that the covariance matrix above is positive definite, a necessary and sufficient condition for which is that all variances be strictly positive and $\rho_{z s}^{2}+\rho_{z \epsilon}^{2}<1$. We also take $V_{z s}$ to be nonnegative, which entails no loss of generality. Finally, to ensure that equilibria are not always fully revealing, we assume that $V_{z \epsilon}$ is nonzero.

As we shall see, the "noise" in this model that prevents equilibrium from being fully revealing arises from the trading of hedger 1 . This agent trades a random amount which depends on his privately observed endowment shock $x$. The endowment shock could equally well be interpreted as a liquidity shock suffered by the agent resulting in a need to rebalance his portfolio. Unlike the usual "noise-trader" or "liquidity-trader" model, hedger 1 maximizes utility and makes inferences like any other rational trader.

The market-maker sets the price equal to his conditional expectation of the asset payoff 
given the order flow, i.e. $p=E(v \mid p, t)$, where

$$
t=q_{S} t_{S}+q_{1} t_{1}+t_{2}
$$

Agents observe the price and order flow. From this observation they can infer the firm's investment level $k$ ( $k$ is $(p, t)$-measurable since the firm's owner, agent 0 , has no private information.) We see from (2) that

$$
p=k E(s \mid p, t)-\frac{c}{2} k^{2}
$$

We look for a linear equilibrium where

$$
E(s \mid p, t)=\lambda s+\mu x
$$

for some parameters $\lambda$ and $\mu$ that will be determined below. Note that it is clear from (4) and (5) that (provided $\lambda$ and $\mu$ are both nonzero) the speculator and hedger 1 have the same information in equilibrium: $\mathcal{I}_{S}=\mathcal{I}_{1}$, which is the partition induced by knowing both $s$ and $x$, while the firm and hedger 2 are unable to isolate $s$ from $x$.

Now agent $i$ 's expected utility is

$$
\begin{aligned}
E\left[-\exp \left(-r_{i} w_{i}\right)\right] & =-E\left[E\left[\exp \left(-r_{i} w_{i}\right) \mid \mathcal{I}_{i}\right]\right] \\
& =-E\left[\exp \left(-r_{i}\left[E\left(w_{i} \mid \mathcal{I}_{i}\right)-\frac{r_{i}}{2} \operatorname{Var}\left(w_{i} \mid \mathcal{I}_{i}\right)\right]\right)\right] .
\end{aligned}
$$

Let

$$
\mathcal{E}_{i}:=E\left(w_{i} \mid \mathcal{I}_{i}\right)-\frac{r_{i}}{2} \operatorname{Var}\left(w_{i} \mid \mathcal{I}_{i}\right)
$$

The agent's optimization problem reduces to choosing a position $t_{i}$ to maximize $\mathcal{E}_{i}$ given his information. From the expression (1) for $w_{i}$ :

$$
\mathcal{E}_{i}=E\left(e_{i} \mid \mathcal{I}_{i}\right)+t_{i}\left[E\left(v \mid \mathcal{I}_{i}\right)-p\right]-\frac{r_{i}}{2}\left[\operatorname{Var}\left(e_{i} \mid \mathcal{I}_{i}\right)+t_{i}^{2} \operatorname{Var}\left(v \mid \mathcal{I}_{i}\right)+2 t_{i} \operatorname{cov}\left(v, e_{i} \mid \mathcal{I}_{i}\right)\right]
$$

The optimal portfolio is therefore

$$
t_{i}=\frac{E\left(v \mid \mathcal{I}_{i}\right)-p-r_{i} \operatorname{cov}\left(v, e_{i} \mid \mathcal{I}_{i}\right)}{r_{i} \operatorname{Var}\left(v \mid \mathcal{I}_{i}\right)}
$$

Proposition 3.1. There exists a unique linear equilibrium. The price function is

$$
p=\frac{1}{2 c}(\lambda s+\mu x)^{2},
$$


the equilibrium investment is

$$
k=\frac{1}{c}(\lambda s+\mu x),
$$

the equilibrium holdings of the agents are given by

$$
\begin{aligned}
t_{S} & =\frac{(1-\lambda) s-\mu x}{r_{S} k V_{\epsilon}}, \\
t_{1} & =\frac{(1-\lambda) s-\left(\mu+r_{1} V_{z \epsilon}\right) x}{r_{1} k V_{\epsilon}}, \\
t_{2} & =-\frac{(1-\lambda) V_{z s}+V_{z \epsilon}}{k\left[(1-\lambda) V_{s}+V_{\epsilon}\right]}
\end{aligned}
$$

and the order flow is

$$
t=\frac{c q_{1} V_{z \epsilon}^{2} V_{x}}{q V_{\epsilon} V_{s}}-\frac{c\left[(1-\lambda) V_{z s}+V_{z \epsilon}\right]}{\left.(\lambda s+\mu x) \mid(1-\lambda) V_{s}+V_{\epsilon}\right]}
$$

where

$$
\begin{aligned}
& \lambda=\frac{q^{2} V_{s}}{V_{z \epsilon}^{2} V_{x}+q^{2} V_{s}}, \\
& \mu=-\frac{q V_{z \epsilon} V_{s}}{V_{z \epsilon}^{2} V_{x}+q^{2} V_{s}},
\end{aligned}
$$

and

$$
q:=\frac{q_{S} r_{S}^{-1}+q_{1} r_{1}^{-1}}{q_{1}}
$$

The numerator of $q$ is the risk tolerance-weighted average of the mass of traders who know the signal $s$ (in equilibrium). It measures the intensity of informed trading. The mass of "random" hedgers $q_{1}$, on the other hand, is a measure of the intensity of "noise trading." Thus $q$ is the signal to noise ratio. Indeed $\left|\frac{\lambda}{\mu}\right|$ is strictly increasing in $q$ : a higher relative intensity of informed trading makes the price more revealing. It is worth noting that $\lambda$ is also strictly increasing in $q$ and induces a bijection from $(0, \infty)$ to $(0,1)$. This allows us to work with $\lambda$ or $q$ interchangeably - as $q$ goes from zero to infinity, or equivalently $\lambda$ goes from zero to one, the equilibrium goes from completely nonrevealing to fully revealing.

The level of investment is more responsive to the share price the lower is the cost of investment (measured by the parameter $c$ ). This feeds back into the equilibrium share price. The lower is $c$, the stronger is the feedback effect.

In this equilibrium uninformed agents can infer $(\lambda s+\mu x)$ from the price and the order flow. If they were not allowed to condition on the order flow, they would be able to infer only the absolute value of $(\lambda s+\mu x)$ from the price. Alternatively, we could assume that 
agents can condition only on prices if there were some other way of revealing the sign of $(\lambda s+\mu x)$, for example a futures contract on the firm's output (i.e. an asset with payoff $y)$, whose equilibrium price can also be used to make inferences.

From Proposition 3.1 we can easily calculate the mean and variance of the share price.

COROLlaRY 3.2. The mean and variance of the share price are as follows:

$$
\begin{gathered}
E(p)=\frac{\lambda V_{s}}{2 c}, \\
\operatorname{Var}(p)=\frac{\lambda^{2} V_{s}^{2}}{2 c^{2}} .
\end{gathered}
$$

With a greater intensity of informed trading and/or a lower cost of investment, both the average share price and the volatility of the share price are higher.

\section{Welfare Analysis}

We measure agents' welfare in equilibrium in terms of their certainty-equivalent wealth. We denote this by $\mathcal{U}_{i}$ for agent $i$ and for convenience we refer to it as the agent's payoff:

$$
\begin{aligned}
\mathcal{U}_{i} & :=-\frac{1}{r_{i}} \ln \left[-E U_{i}\left(w_{i}\right)\right] \\
& =-\frac{1}{r_{i}} \ln \left[E\left[\exp \left(-r_{i} w_{i}\right)\right]\right],
\end{aligned}
$$

where expectations are taken over the ex ante distribution of wealth in equilibrium. Notice that, for agents $S$ and 1, wealth is not normally distributed ex ante, and therefore certaintyequivalent wealth cannot be computed by the usual mean-variance formula (the welfare analysis in Leland (1992) is therefore incorrect). In the expression for agent $i$ 's terminal wealth,

$$
w_{i}=t_{i}(v-p)+e_{i}\left(x_{i}, z\right)
$$

$t_{i}, v$, and $p$ are all normal, while $e_{i}$ is either zero (in the case of agent $S$ ) or the product of two normals (agent 1).

Proposition 4.1. The expected value of the firm in equilibrium is

$$
E(v)=\frac{\lambda V_{s}}{2 c} .
$$


The payoffs of the agents are:

$$
\begin{aligned}
& \mathcal{U}_{S}=\frac{1}{2 r_{S}} \ln \left[1+(1-\lambda) V_{s} V_{\epsilon}^{-1}\right] \\
& \left.\mathcal{U}_{1}=\frac{1}{2 r_{1}} \ln \left[\left(1-r_{1}^{2} V_{x} V_{z}\right)\left[1+(1-\lambda)^{2} V_{s} V_{\epsilon}^{-1}\right]+\left(\mu+r_{1} \mid(1-\lambda) V_{z s}+V_{z \epsilon}\right]\right)^{2} V_{x} V_{\epsilon}^{-1}\right] \\
& \mathcal{U}_{2}=\frac{r_{2}}{2}\left[\frac{\left[(1-\lambda) V_{z s}+V_{z \epsilon}\right]^{2}}{(1-\lambda) V_{s}+V_{\epsilon}}-V_{z}\right] .
\end{aligned}
$$

Note that the expected value of the firm is in fact $\mathcal{U}_{0}$, the payoff of agent 0 who is the initial owner of the firm. It is also the expected share price (since $E(v)=E[E(v \mid p, t)]=$ $E(p))$. We now wish to assess the welfare impact of changing $q$, the relative intensity of informed trading.

Proposition 4.2. With respect to $q$, the expected value of the firm $E(v)$ is increasing; the speculator's payoff $\mathcal{U}_{S}$ is decreasing; and the uninformed hedger's payoff $\mathcal{U}_{2}$ is

(a) decreasing if and only if $\left|\beta_{z s}-\beta_{z \epsilon}\right| \leq \beta_{z s}$,

(b) increasing if and only if $\left|\beta_{z s}-\beta_{z \epsilon}\right| \geq V_{y} V_{\epsilon}^{-1} \beta_{z s}$, and

(c) strictly convex and attains a minimum if and only if $\beta_{z s}<\left|\beta_{z s}-\beta_{z \epsilon}\right|<V_{y} V_{\epsilon}^{-1} \beta_{z s}$.

Here we use the terms increasing and decreasing in the strict sense. Since $\lambda$ is increasing in $q$, the statements regarding the firm's value and the speculator's payoff are immediate from Proposition 4.1. The interpretation is straightforward: a higher relative intensity of informed trading causes the price and order flow to be more informative, and the firm's investment decisions are improved. Also, an individual speculator's payoff $\mathcal{U}_{S}$ is decreasing in $q$ since a more revealing trading process means less favourable opportunities for speculative profit.

The comparative statics for the uninformed hedger are more subtle. Recall that $\beta_{g h}$ is the regression coefficient from the regression of $g$ on $h$. Whether hedger 2 prefers to be less or more informed in equilibrium depends on the relative size of the two betas, $\beta_{z s}$ and $\beta_{z \epsilon}$. A bigger $\beta_{z s}$ means a stronger Hirshleifer effect: observing a signal that is highly informative about endowments reduces risk-sharing opportunities in the market. On the other hand, the bigger is the magnitude of $\beta_{z \epsilon}$, the more desirable it is to obtain a good estimate of $s$ so that the endowment risk associated with $\epsilon$ can be hedged more effectively. If $\beta_{z \epsilon}$ is very small relative to $\beta_{z s}$ (case (a)), the Hirshleifer effect dominates and the hedger is worse off as informed trading increases and more information is revealed by the market. In case 
(b) the opposite is true: the hedger prefers more revelation to less since the speculator's information resolves a lot of uncertainty regarding the asset payoff and not much regarding the endowment. In the intermediate case (c), the hedger prefers the equilibrium to be either fully revealing or not revealing at all.

Empirical evidence on trading volume in financial markets suggests that the dominant case is (c). It has been observed that the typical daily pattern of trading volume is U-shaped, with heavy trading in the morning and late afternoon and relatively little activity in the middle of the day. If prices are more revealing as the trading day progresses, uninformed hedgers would prefer to trade either at the open or the close. A theory of intraday patterns that exploits this idea is presented in Marín and Rahi (1996).

\section{Conclusions}

In this paper, we have presented a general model of a security market with agents who trade for informational and hedging motives. The model also incorporates the feedback effect of investment policy (as a function of the price) back onto price formation.

We first prove the "no-loss" result: hedgers who have no information other than publicly observed market signals cannot lose money to informed traders. To analyze the welfare effects of informed trading, we use a parametric model where all agents are rational utilitymaximizers and we compute explicit closed-form solutions for their equilibrium utility levels. A more informative price is always beneficial with regard to real investment decisions, while reducing the returns from informed speculation. For uninformed hedgers, the answer is not unambiguous: it depends on the whether the information being revealed is primarily about the hedger's endowment risk which he wants to insure (the Hirshleifer effect), or information that resolves asset payoff uncertainty thus improving hedging efficiency. 


\section{APPENDIX}

Lemma A.1. Suppose A is a symmetric $m \times m$ matrix, $\mathbf{b}$ is an $m$-vector, $d$ is a scalar, and $\mathbf{w}$ is an $m$-dimensional normal variate: $\mathbf{w} \sim N(\mathbf{0}, \mathbf{\Sigma}), \mathbf{\Sigma}$ positive definite. Then $E\left[\exp \left(\mathbf{w}^{\top} \mathbf{A} \mathbf{w}+\mathbf{b}^{\top} \mathbf{w}+d\right)\right.$ is well-defined if and only if $(\mathbf{I}-2 \mathbf{\Sigma} \mathbf{A})$ is positive definite, and

$$
E\left[\exp \left(\mathbf{w}^{\top} \mathbf{A} \mathbf{w}+\mathbf{b}^{\top} \mathbf{w}+d\right)=|\mathbf{I}-2 \mathbf{\Sigma} \mathbf{A}|^{-\frac{1}{2}} \exp \left[\frac{1}{2} \mathbf{b}^{\top}(\mathbf{I}-2 \mathbf{\Sigma} \mathbf{A})^{-1} \mathbf{\Sigma} \mathbf{b}+d\right] .\right.
$$

\section{Proof.}

$$
\begin{aligned}
& E\left[\exp \left(\mathbf{w}^{\top} \mathbf{A} \mathbf{w}+\mathbf{b}^{\top} \mathbf{w}+d\right)\right] \\
& =\int_{\boldsymbol{R}^{m}} \exp \left(\mathbf{w}^{\top} \mathbf{A} \mathbf{w}+\mathbf{b}^{\top} \mathbf{w}+d\right)(2 \pi)^{-\frac{m}{2}}|\mathbf{\Sigma}|^{-\frac{1}{2}} \exp \left(-\frac{1}{2} \mathbf{w}^{\top} \mathbf{\Sigma}^{-1} \mathbf{w}\right) d \mathbf{w} \\
& =\int_{\mathbb{R}^{m}}(2 \pi)^{-\frac{m}{2}}|\mathbf{\Sigma}|^{-\frac{1}{2}} \exp \left[-\frac{1}{2} \mathbf{w}^{\top}\left(\boldsymbol{\Sigma}^{-1}-2 \mathbf{A}\right) \mathbf{w}+\mathbf{b}^{\top} \mathbf{w}+d\right] d \mathbf{w} \\
& =\int_{\mathbb{R}^{m}}(2 \pi)^{-\frac{m}{2}}|\mathbf{\Sigma}|^{-\frac{1}{2}} \exp \left[-\frac{1}{2}(\mathbf{w}-\overline{\mathbf{w}})^{\top}\left(\boldsymbol{\Sigma}^{-1}-2 \mathbf{A}\right)(\mathbf{w}-\overline{\mathbf{w}})+\frac{1}{2} \mathbf{b}^{\top}\left(\boldsymbol{\Sigma}^{-1}-2 \mathbf{A}\right)^{-1} \mathbf{b}+d\right] d \mathbf{w} \\
& =|\mathbf{\Sigma}|^{-\frac{1}{2}}\left|\left(\mathbf{\Sigma}^{-1}-2 \mathbf{A}\right)^{-1}\right|^{\frac{1}{2}} \exp \left[\frac{1}{2} \mathbf{b}^{\top}\left(\mathbf{\Sigma}^{-1}-2 \mathbf{A}\right)^{-1} \mathbf{b}+d\right]
\end{aligned}
$$

where $\overline{\mathbf{w}}=\left(\boldsymbol{\Sigma}^{-1}-2 \mathbf{A}\right)^{-1} \mathbf{b}$. The result follows immediately.

Proof of Proposition 3.1. The firm solves the problem:

$$
\max _{k \in \boldsymbol{R}} k E(s \mid p, t)-\frac{c}{2} k^{2},
$$

giving $k=c^{-1} E(s \mid p, t)=c^{-1}(\lambda s+\mu x)$, using (4). Also, from (4) and (5),

$$
p=k(\lambda s+\mu x)-\frac{c}{2} k^{2} .
$$

By substituting in the equilibrium $k$ we obtain the desired expression for the price function.

For the speculator, using (2) and (9), and standard properties of the normal distribution (see, for example, Anderson (1984)), we get

$$
\begin{aligned}
t_{S} & =\frac{E(v \mid s)-p}{r_{S} \operatorname{Var}(v \mid s)} \\
& =\frac{k s-\frac{c}{2} k^{2}-\left[k(\lambda s+\mu x)-\frac{c}{2} k^{2}\right]}{r_{S} k^{2} V_{\epsilon}} \\
& =\frac{(1-\lambda) s-\mu x}{r_{S} k V_{\epsilon}} .
\end{aligned}
$$


Similarly for the hedgers

$$
\begin{aligned}
& t_{1}=\frac{(1-\lambda) s-\left(\mu+r_{1} V_{z \epsilon}\right) x}{r_{1} k V_{\epsilon}}, \\
& t_{2}=-\frac{\left(\operatorname{cov}(z, s \mid p, t)+V_{z \epsilon}\right)}{k\left(\operatorname{Var}(s \mid p, t)+V_{\epsilon}\right)} .
\end{aligned}
$$

Substituting into (3) we can write the aggregate order flow as

$$
t=t_{2}+\frac{q_{1}}{k V_{\epsilon}} \cdot \tau
$$

where

$$
\tau:=q(1-\lambda) s-\left(q \mu+V_{z \epsilon}\right) x,
$$

and $q$ is as defined in the statement of the proposition. We proceed under the assumption that observing prices and the order flow is equivalent to observing $(\lambda s+\mu x)$. As we shall see, this will turn out to be true in equilibrium. Then uninformed agents can infer $k$, so that

$$
E(s \mid p, t)=E(s \mid \tau)=q(1-\lambda) V_{s} V_{\tau}^{-1} \tau .
$$

Comparing coefficients with (5) we get:

$$
\begin{aligned}
& \lambda=q^{2}(1-\lambda)^{2} V_{s} V_{\tau}^{-1}, \\
& \mu=-q(1-\lambda)\left(q \mu+V_{z \epsilon}\right) V_{s} V_{\tau}^{-1} .
\end{aligned}
$$

Therefore

$$
1-\lambda=\left(q \mu+V_{z \epsilon}\right)^{2} V_{x} V_{\tau}^{-1}
$$

and

$$
\frac{1-\lambda}{\mu}=-\frac{\left(q \mu+V_{z \epsilon}\right) V_{x}}{q(1-\lambda) V_{s}}
$$

Cross-multiplying gives

$$
q(1-\lambda)^{2} V_{s}+q \mu^{2} V_{x}=-\mu V_{z \epsilon} V_{x} .
$$

This can be substituted into the expression for $V_{\tau}$ (which follows immediately from the definition of $\tau$ ), to give:

$$
V_{\tau}=V_{z \epsilon} V_{x}\left(q \mu+V_{z \epsilon}\right) .
$$

Substituting this expression into (12) and (13) gives:

$$
\begin{aligned}
& \lambda=-\frac{q \mu}{V_{z \epsilon}}, \\
& \mu=-\frac{q(1-\lambda) V_{s}}{V_{z \epsilon} V_{x}} .
\end{aligned}
$$


These equations are linear in $\mu$ and $\lambda$ and can be solved to obtain the desired result.

From (14) and (15) we get

$$
\begin{aligned}
(1-\lambda)^{2} V_{s}+\mu^{2} V_{x} & =-q^{-1} \mu V_{z \epsilon} V_{x} \\
& =(1-\lambda) V_{s} .
\end{aligned}
$$

From this we can deduce that

$$
\lambda^{2} V_{s}+\mu^{2} V_{x}=\lambda V_{s} .
$$

The conditional moments for hedger 2, who observes only the price and order flow, are equivalent to the moments conditional on $(\lambda s+\mu x)$. Using the standard properties of the normal, together with (17), we get:

$$
\begin{aligned}
\operatorname{Var}(s \mid p, t) & =(1-\lambda) V_{s} \\
\operatorname{cov}(z, s \mid p, t) & =(1-\lambda) V_{z s} .
\end{aligned}
$$

Substituting into (11) we obtain the desired formula for $t_{2}$. The equilibrium order flow can now be readily computed.

Finally, using (17),

$$
E(s \mid p, t)=E(s \mid \lambda s+\mu x)=\lambda s+\mu x
$$

thus verifying the conjectured form (5) for the equilibrium.

Proof of Corollary 3.2. From the moment generating function of the normal distribution, if $X \sim N\left(0, \sigma^{2}\right)$, then $E\left(X^{2}\right)=\sigma^{2}$ and $\operatorname{Var}\left(X^{2}\right)=2 \sigma^{4}$. Now we obtain the result by using the expression for the price function from Proposition 3.1 and equation (17).

Proof of Proposition 4.1. Note that $E(v)=E[E(v \mid p, t)]=E(p)$. The formula for the firm's value follows from Corollary 3.2 .

From (6), (7) and (10),

$$
\mathcal{U}_{i}=-\frac{1}{r_{i}} \ln \left[E\left[\exp \left(-r_{i} \mathcal{E}_{i}\right)\right]\right]
$$

Using (8) and (9), in equilibrium,

$$
\begin{aligned}
\mathcal{E}_{i} & =E\left(e_{i} \mid \mathcal{I}_{i}\right)-\frac{r_{i}}{2} \operatorname{Var}\left(e_{i} \mid \mathcal{I}_{i}\right)+t_{i}\left[E\left(v \mid \mathcal{I}_{i}\right)-p-r_{i} \operatorname{cov}\left(v, e_{i} \mid \mathcal{I}_{i}\right)\right]-\frac{r_{i}}{2} t_{i}^{2} \operatorname{Var}\left(v \mid \mathcal{I}_{i}\right) \\
& =E\left(e_{i} \mid \mathcal{I}_{i}\right)-\frac{r_{i}}{2} \operatorname{Var}\left(e_{i} \mid \mathcal{I}_{i}\right)+\frac{r_{i}}{2} t_{i}^{2} \operatorname{Var}\left(v \mid \mathcal{I}_{i}\right) .
\end{aligned}
$$


Setting $e_{S}=0$ in (19), substituting for the equilibrium holding of the speculator from Proposition 3.1, and using Lemma A.1, we obtain

$$
\left.\mathcal{U}_{S}=\frac{1}{2 r_{S}} \ln \left[1+V_{\epsilon}^{-1} \mid(1-\lambda)^{2} V_{s}+\mu^{2} V_{x}\right]\right] .
$$

The formula for the speculator's payoff follows from (16). Noting that hedger 1 has the same information in equilibrium as the speculator, we can derive $\mathcal{U}_{1}$ by using (19), Proposition 3.1, and Lemma A.1. For hedger 2,

$$
\mathcal{E}_{2}=E(z \mid p, t)-\frac{r_{2}}{2} \operatorname{Var}(z \mid p, t)+\frac{r_{2}}{2} t_{2}^{2} \operatorname{Var}(v \mid p, t)
$$

Analogous to (18), we get

$$
\begin{aligned}
E(z \mid p, t) & =\frac{V_{z s}}{V_{\theta}}[\lambda s+\mu x] \\
\operatorname{Var}(z \mid p, t) & =V_{z}-\frac{V_{z s}^{2}}{V_{s}} \lambda \\
\operatorname{Var}(v \mid p, t) & =k^{2}\left[(1-\lambda) V_{s}+V_{\epsilon}\right] .
\end{aligned}
$$

Substituting into (19) and using Proposition 3.1 and Lemma A.1 we obtain the formula for $u_{2}$.

Proof of Proposition 4.2. Note that $\lambda$ is increasing in $q$. The comparative statics for $E(v)$ and $U_{S}$ are immediate from Proposition 4.1. From the expression for $\mathcal{U}_{2}$ we see that if $V_{z s}=0, \mathcal{U}_{2}$ is increasing in $q$. This case is covered by item (c) in the proposition. Henceforth we restrict $V_{z s}$ to be strictly positive (note our convention that $V_{z s} \geq 0$ ). Differentiating $U_{2}$ with respect to $\lambda$, we obtain two critical points:

$$
\begin{aligned}
& \lambda^{*}=1+\frac{V_{\epsilon}}{V_{s}} \cdot \frac{\beta_{z \epsilon}}{\beta_{z s}} \\
& \lambda^{* *}=1+\frac{V_{\epsilon}}{V_{s}}\left(2-\frac{\beta_{z \epsilon}}{\beta_{z s}}\right) .
\end{aligned}
$$

Also we see that

$$
\operatorname{sgn}\left[\frac{\partial^{2} \mathcal{U}_{2}}{(\partial \lambda)^{2}}\right]_{\lambda=\lambda^{*}}=-\operatorname{sgn}\left[\frac{\partial^{2} \mathcal{U}_{2}}{(\partial \lambda)^{2}}\right]_{\lambda=\lambda^{*}}=\operatorname{sgn}\left(\beta_{z s}-\beta_{z \epsilon}\right) .
$$

The comparative statics for $\mathcal{U}_{2}$ can now be verified by considering each case in turn and restricting $\lambda$ to the unit interval $(0,1)$. 


\section{REFERENCES}

1. Akerlof, G. A. (1970): "The Market for 'Lemons': Quality Uncertainty and the Market Mechanism," Quarterly Journal of Economics, 84, 488-500.

2. Allen, F. and D. Gale (1994): Financial Innovation and Risk Sharing. Cambridge, MA: MIT Press.

3. Anderson, T. W. (1984): An Introduction to Multivariate Statistical Analysis (2nd ed.). New York: Wiley.

4. Arrow, K. J. (1953): "Le Rôle des Valeurs Boursières pour la Répartition la Meilleure des Risques," Econometrie, 11, 41-47. English translation (1964): "The Role of Securities in the Optimal Allocation of Risk Bearing," Review of Economic Studies, 31, 91-96.

5. Ausubel, L. M. (1990): "Insider Trading in a Rational Expectations Economy," American Economic Review, 80, 1022-1041.

6. Bhattacharya, S. and Nicodano, G. (1995): "Insider Trading, Investment, and Welfare: A Perturbation Analysis," working paper, London School of Economics.

7. Boot, A. W. A. and A. V. Thakor (1996): "Banking Scope and Financial Innovation," working paper, Indiana University.

8. Bresnahan, T., P. Milgrom and J. Paul (1992): "The Real Output of the Stock Exchange," in Z. Griliches (Ed.), Oıtput Measurement in the Service Sectors. Chicago: University of Chicago Press, 195-216.

9. Dennert, J. (1990): "Insider Trading and the Allocation of Risks," working paper, Universität Basel.

10. Diamond, D. W. and R. E. Verrecchia (1981): "Information Aggregation in a Noisy Rational Expectations Economy," Journal of Financial Economics, 9, 221-235.

11. Diamond, P. (1967): "The Role of a Stock Market in a General Equilibrium Model with Technological Uncertainty," American Economic Review, 57, 759-776. 
12. Dow, J. and G. Gorton (1995): "Stock Market Efficiency and Economic Efficiency: Is there a Connection?," working paper, London Business School.

13. Fama, E. (1976): Foundations of Finance. New York: Basic Books.

14. Fishman, M. J. and K. M. Hagerty (1992): "Insider Trading and the Efficiency of Stock Prices," Rand Journal of Economics, 23, 106-122.

15. Glosten, L. R. (1989): "Insider Trading, Liquidity, and the Role of the Monopolist Specialist," Journal of Business, 62, 211-235.

16. Glosten, L. R. and P. R. Milgrom (1985): "Bid, Ask and Transaction Prices in a Specialist Market with Heterogeneously Informed Traders," Journal of Financial Economics, $14,71-100$.

17. Grossman, S. J. (1977): "The Efficiency of Futures Markets, Noisy Rational Expectations and Informational Externalities," Review of Economic Studies, 44, 431-449.

18. Grossman, S. J. and J. E. Stiglitz (1980): "On the Impossibility of Informationally Efficient Markets," American Economic Review, 70, 393-408.

19. Habib, M. A., D. B. Johnsen and N. Y. Naik (1996): "Spin-offs and Information," working paper, London Business School.

20. Henrotte, P. (1992); "Market Behaviour with Endogenous Production and Asymmetric Information," working paper, Stanford University.

21. Hirshleifer, J. (1971): "The Private and Social Value of Information and the Reward to Inventive Activity," American Economic Review, 61, 561-574.

22. Holmström, B. and J. Tirole (1993): "Market Liquidity and Performance Monitoring," Journal of Political Economy, 101, 678-709.

23. King, M. A. and A. Roëll (1988): "Insider Trading," Economic Policy, 5, 165-187.

24. Leland, H. L. (1992): "Insider Trading: Should it be Prohibited?," Journal of Political Economy, 100, 859-887.

25. Manne, A. (1966): Insider Trading and the Stock Market. New York: Free Press. 
26. Manove, M. (1989): "The Harm from Insider Trading and Informed Speculation," Quarterly Journal of Economics, 104, 823-845.

27. Marín, J. M. and R. Rahi (1995): "Information Revelation and Market Incompleteness," working paper, Birkbeck College, University of London.

28. Marín, J. M. and R. Rahi (1996): "A Theory of Intraday Patterns in Financial Markets," in preparation.

29. Roberts, H. V. (1967): "Statistical versus Clinical Prediction of the Stock Market," working paper, University of Chicago.

30. Spiegel, M. and A. Subrahmanyam (1992): "Informed Speculation and Hedging in a Noncooperative Securities Market," Review of Financial Studies, 5, 307-331.

31. Tobin, J. (1978): “A Proposal for International Monetary Reform," Eastern Economic Journal. 


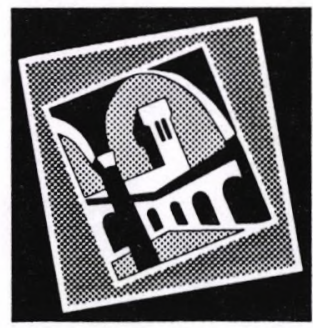

EUI WORKING PAPERS

EUI Working Papers are published and distributed by the European University Institute, Florence

Copies can be obtained free of charge - depending on the availability of stocks - from:

The Publications Officer European University Institute Badia Fiesolana

I-50016 San Domenico di Fiesole (FI) Italy 


\section{Publications of the European University Institute}

To

The Publications Officer

European University Institute

Badia Fiesolana

I-50016 San Domenico di Fiesole (FI) - Italy

Telefax No: +39/55/4685 636

E-mail: publish@datacomm.iue.it

From

Name

Address.

$\checkmark$ Please send me a complete list of EUI Working Papers $\square$ Please send me a complete list of EUI book publications $\square$ Please send me the EUI brochure Academic Year 1997/98

Please send me the following EUI Working Paper(s):

No, Author

Title:

No, Author

Title:

No, Author

Title:

No, Author

Title:

Date

Signature 


\section{Working Papers of the Department of Economics Published since 1994}

ECO No. 96/1

Ana Rute CARDOSO

Earnings Inequality in Portugal: High and Rising?

ECO No. 96/2

Ana Rute CARDOSO

Workers or Employers: Who is Shaping

Wage Inequality?

ECO No. 96/3

David F. HENDRY/Grayham E. MIZON

The Influence of A.W.H. Phillips on

Econometrics

ECO No. 96/4

Andrzej BANIAK

The Multimarket Labour-Managed Firm and the Effects of Devaluation

ECO No. 96/5

Luca ANDERLINL/Hamid

SABOURIAN

The Evolution of Algorithmic Learning:

A Global Stability Result

ECO No. 96/6

James DOW

Arbitrage, Hedging, and Financial

Innovation

ECO No. 96/7

Marion KOHLER

Coalitions in International Monetary

Policy Games

ECO No. 96/8

John MICKLEWRIGHT/Gyula NAGY

A Follow-Up Survey of Unemployment Insurance Exhausters in Hungary

ECO No. 96/9

Alastair McAULEY/John

MICKLEWRIGHT/Aline COUDOUEL

Transfers and Exchange Between

Households in Central Asia

ECO No. 96/10

Christian BELZIL/Xuelin ZHANG

Young Children and the Search Costs of Unemployed Females
ECO No. 96/11

Christian BELZIL

Contiguous Duration Dependence and

Nonstationarity in Job Search: Some

Reduced-Form Estimates

ECO No. 96/12

Ramon MARIMON

Learning from Learning in Economics

ECO No. 96/13

Luisa ZANFORLIN

Technological Diffusion, Learning and Economic Performance: An Empirical Investigation on an Extended Set of Countries

ECO No. 96/14

Humberto LÓPEZ/Eva ORTEGA/Angel UBIDE

Explaining the Dynamics of Spanish

Unemployment

ECO No. 96/15

Spyros VASSILAKIS

Accelerating New Product Development by Overcoming Complexity Constraints

ECO No. 96/16

Andrew LEWIS

On Technological Differences in

Oligopolistic Industries

ECO No. 96/17

Christian BELZIL

Employment Reallocation, Wages and the Allocation of Workers Between

Expanding and Declining Firms

ECO No. 96/18

Christian BELZIL/Xuelin ZHANG

Unemployment, Search and the Gender Wage Gap: A Structural Model

ECO No. 96/19

Christian BELZIL

The Dynamics of Female Time Allocation upon a First Birth

ECO No. 96/20

Hans-Theo NORMANN

Endogenous Timing in a Duopoly Model with Incomplete Information 
ECO No. $96 / 21$

Ramon MARIMON/Fabrizio ZILIBOTTI Actual' Versus 'Virtual' Employment in Europe Spain Different?

EeO No. $96 / 22$

Chiara MONFARDINI

Estimating Stochastic Volatility Models

Through Indirect Inference

ECO No. 96/23

Luisa ZANFORLIN

Technological Diffusion, Learning and

Growth: An Empirical Investigation of a

Set of Developing Countries

ECO No. 96/24

Luisa ZANFORLIN

Technological Assimilation, Trade

Patterns and Growth: An Empirical

Investigation of a Set of Developing

Countries

ECO No. 96/25

Giampiero M.GALLO/Massimiliano

MARCELLINO

In Plato's Cave: Sharpening the Shadows of Monetary Announcements

ECO No. 96/26

Dimitrios SIDERIS

The Wage-Price Spiral in Greece: An

Application of the LSE Methodology in

Systems of Nonstationary Variables

ECO No. 96/27

Andrei SAVKOV

The Optimal Sequence of Privatization in

Transitional Economies

ECO No. 96/28

Jacob LUNDQUIST/Dorte VERNER

Optimal Allocation of Foreign Debt

Solved by a Multivariate GARCH Model

Applied to Danish Data

ECO No. 96/29

Dorte VERNER

The Brazilian Growth Experience in the

Light of Old and New Growth Theories

ECO No. $96 / 30$

Steffen HÖRNIG/Andrea LOFARO/

Louis PHLIPS

How Much to Collude Without Being Detected
ECO No. 96/31

Angel J. UBIDE

The International Transmission of Shocks in an Imperfectly Competitive

International Business Cycle Model

ECO No. 96/32

Humberto LOPEZ/Angel J. UBIDE

Demand, Supply, and Animal Spirits

ECO No. 96/33

Andrea LOFARO

On the Efficiency of Bertrand and

Cournot Competition with Incomplete Information

ECO No. 96/34

Anindya BANERJEE/David F.

HENDRY/Grayham E. MIZON

The Econometric Analysis of Economic

Policy

ECO No. 96/35

Christian SCHLUTER

On the Non-Stationarity of German

Income Mobility (and Some Observations on Poverty Dynamics)

ECO No. $96 / 36$

Jian-Ming ZHOU

Proposals for Land Consolidation and

Expansion in Japan

ECO No. 96/37

Susana GARCIA CERVERO

Skill Differentials in the Long and in the

Short Run. A 4-Digit SIC Level U.S.

Manufacturing Study

深㳕

ECO No. 97/1

Jonathan SIMON

The Expected Value of Lotto when not all Numbers are Equal

ECO No. 97/2

Bernhard WINKLER

Of Sticks and Carrots: Incentives and the Maastricht Road to EMU

ECO No. $97 / 3$

James DOW/Rohit RAHI

Informed Trading, Investment, and Welfare 


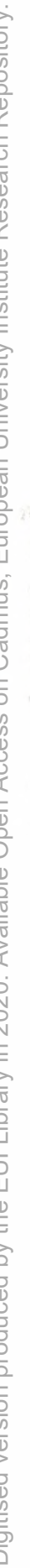


